\title{
1 \\ Hegel's Phenomenological Method and Analysis of Consciousness
}

\author{
Kenneth R. Westphal
}

\section{Introduction}

$\mathrm{H}$ egel's 1807 Phenomenology of Spirit has been widely interpreted in view of his Preface rather than his Introduction. This is unfortunate. Hegel's notoriously rich, ambitious, and exciting Preface is a Preface not only to the Phenomenology but to Hegel's projected philosophical system, which was to contain the Phenomenology as Part 1 and a second work as Part 2 which would cover logic, philosophy of nature, and philosophy of spirit. Hegel's Preface thus greatly surpasses the issues and aims of the Phenomenology itself. ${ }^{1}$ As Hegel insists in his retrospectively written Preface, truth can only be obtained as the result of inquiry, not from initial projections. ${ }^{2}$ Hegel's prospectively written Introduction contains invaluable information about Hegel's issues and methods, especially about epistemological issues addressed throughout the Phenomenology, which examines the possibility of "absolute knowing" or genuine knowledge of "what in truth is,"3 that is, knowledge no longer qualified by any distinction between mere appearance and genuine reality. ${ }^{4}$

Hegel's texts yield richly to the traditional hermeneutical requirements that an adequate interpretation integrates complete textual, historical, and systematic (that is, issues-oriented philosophical) analysis of a text. Meeting these requirements leads to heterodox interpretations, yet also maximally justifies them. Such detailed analysis I have provided elsewhere; here I epitomize the central points of Hegel's Introduction $(\$ 2)$ and first three chapters, "Sense Certainty" $(\$ 3)$, "Perception" $(\$ 4)$, and "Force and Understanding" $(\$ 5)$. I then summarize Hegel's overarching analysis of human knowledge in the Phenomenology $(\$ 6)$. 


\section{Hegel's Introduction}

\subsection{Problems about knowledge and justification}

One key epistemological problem Hegel poses in his Introduction is how legitimately to assess or to establish the truth or falsehood of competing philosophies (PS 55.12-31, 58.10-22/M 48, 52). Hegel recognized that settling controversy about claims to knowledge, whether commonsense, natural-scientific, or philosophical, requires adequate criteria for judging the debate, though the controversy often also concerns those criteria. This threat of vicious circularity and questionbegging ${ }^{5}$ was quintessentially formulated by Sextus Empiricus as the Dilemma of the Criterion:

[I]n order to decide the dispute which has arisen about the criterion [of truth], we must possess an accepted criterion by which we shall be able to judge the dispute; and in order to possess an accepted criterion, the dispute about the criterion must first be decided. And when the argument thus reduces itself to a form of circular reasoning the discovery of the criterion becomes impracticable, since we do not allow [those who make knowledge claims] to adopt a criterion by assumption, while if they offer to judge the criterion by a criterion we force them to a regress ad infinitum. And furthermore, since demonstration requires a demonstrated criterion, while the criterion requires an approved demonstration, they are forced into circular reasoning. (Sextus Empiricus, PH 2:4 \$20; cf. 1:14 \$\$116-17)

Hegel refers in passing to this Dilemma (henceforth: 'the Dilemma') in his 1801 essay on skepticism (Skept., GW 4:212.9), though he then agreed with Schelling that only the "limited" claims of the understanding confronted this problem, which was surpassed by the "infinite" claims of reason obtained through intellectual intuition. A satirical critique of intellectual intuition led Hegel to realize that intuitionism in any substantive form, ${ }^{6}$ including Schelling's, is cognitively bankrupt because it can only issue claims without justifying reasons, and "one mere claim is worth as much as another" (PS 55.21-24/M 49). Conflicting claims suffice to show that at least one of them is false, though none of them provide a basis for determining which are false and which, if any, are true. ${ }^{7}$

Hegel restates Sextus' Dilemma in the middle of the Introduction (PS 9:58.1222/M 52). Hegel recognized that it is a genuine philosophical problem; that it disposes of both coherentist and foundationalist models of justification, and so disposes of the two traditional models of knowledge (scientia and historia), although this Dilemma does not ultimately justify skepticism about ordinary, scientific, or philosophical knowledge.

Against coherentism, the Dilemma raises the charge of vicious circularity. On the basis of coherence alone it is hard to distinguish in any principled way between genuine progress in our knowledge in contrast to mere change in belief. Coherentism's most able and persistent contemporary advocate, Laurence BonJour, has conceded that coherentism cannot meet this challenge. ${ }^{8}$ 
Foundationalist models of justification typically distinguish between historia and scientia. Historical knowledge (historia) derives from sensory and memorial data; rational knowledge (scientia) is logically deduced from first principles. ${ }^{9}$ Both models involve justifying conclusions by deriving them unilaterally from basic foundations: justification flows from basic foundations to other, derived claims, not vice versa. This holds whether justificatory relations are strictly deductive or whether they involve other kinds of rules of inference (e.g., induction, abduction) or weaker forms of basing relations.

The Dilemma exposes foundationalist models of justification as dogmatic and question-begging because such models cannot be justified to those who fundamentally dispute either the foundations or the basing relations invoked by any foundationalist theory, or the foundationalist model itself, because this model understands justification solely in terms of derivation from first premises of whatever kind. In principle, foundationalism preaches to the (nearly) converted, and begs the question against those who dissent; once they are disputed, foundationalism cannot justify its criteria of truth or of justification. ${ }^{10}$

Hegel recognized that solving the Dilemma requires a fallibilist, pragmatic, socio-historical account of rational justification which is consistent with realism about the objects of knowledge (and with strict objectivity about normative principles). Hegel's account of rational justification is based in part in his phenomenological method, which is based on Hegel's account of the self-critical structure of consciousness, which is embedded in Hegel's account of forms of consciousness.

\subsection{Forms of consciousness}

A "form" (Gestalt) of consciousness comprises a pair of basic principles, applied by their ideal exponent to their intended domains. ${ }^{11}$ One principle specifies the kind of knowledge that form presumes to have; the other specifies the kind of objects it presumes to know. Hegel calls these two principles a form of consciousness's "certainty" (Gewißheit). Put idiomatically, these principles specify what a form of consciousness is sure the world and its knowledge of it are like.

A form of consciousness, so specified, is neutral between an individual's view and a group's collective outlook, and between historically identifiable and merely possible views of human knowledge and its objects. Historical epochs and extant philosophies are, Hegel contends, variations on the forms of consciousness examined in the Phenomenology, because both forms of consciousness and historically identifiable views devolve from central characteristics of human consciousness. This is one point of Hegel's claim that the Phenomenology presents "the path of the soul which is making its way through the sequence of its own transformations as through waystations prescribed by its very nature ..." (PS 55.36-39/M 49).

By grasping some aspect of its own nature as a cognizer, each form of consciousness adopts a particular principle concerning what knowledge is. This epistemic principle implies certain constraints on the objects of knowledge. Therefore the 
adoption of an epistemic principle brings with it a concomitant ontological principle. To take a pair of epistemic and ontological principles as a form of consciousness allows latitude for developing from less to more sophisticated versions. To consider such a pair of principles as a form of consciousness examines them only as they can be adopted and employed by consciousness in attempting to comprehend its intended objects. ${ }^{12}$

Hegel proposes to examine such concepts as 'subject', 'object', 'knowledge', and 'world'. These abstract terms specify little. Hence Hegel examines particular sets of specific versions of these conceptions by examining their ideal employment by each form of consciousness. To solve the Dilemma and to avoid petitio principii, Hegel's justification of his own views results from an internal, self-critical assessment of every form of consciousness (see below, \$6). Examining the insights and oversights of each form of consciousness enables us, Hegel's readers, to understand the adequate specification of these abstract conceptions Hegel provides at the end of the Phenomenology.

\subsection{The possibility of constructive self-criticism}

Against "coherentist," "circular," or "dialectical" theories of justification, Sextus' Dilemma raises the trope of vicious circularity. However, this horn of the Dilemma is defeated, and is shown to be merely a skeptical trope, by Hegel's account of the possibility of constructive self- and mutual criticism. The key points in Hegel's account are these.

In the Introduction, Hegel analyses this unassuming claim about human consciousness:

consciousness distinguishes from itself something to which it at the same time relates itself; or, as this is expressed, this something is something for consciousness. The determinate side of this relation, or the being of something for a consciousness, is knowledge. From this being for an other, however, we distinguish the being in itself; that which is related to knowledge is at the same time distinguished from it and is posited as existing also outside this relation. (PS 58.25-31/M 52)

Hegel analyzes this bit of common sense to distinguish the object itself from our conception of it, and ourselves as actual cognitive subjects from our self-conception as cognitive subjects. Hegel analyses our experience of an object and our experience of ourselves as cognitive subjects, as resulting from our use of our conceptions in attempting to know our intended objects: our experience of the object results from our use of our conception of the object in attempting to know the object itself. Likewise, our self-experience as cognizant beings results from our use of our cognitive self-conception in attempting to know ourselves in our cognitive engagements. Hegel distinguishes these aspects of consciousness as a cognitive relation to objects:
A. Our conception of the object.
1. Our cognitive self-conception.
B. Our experience of the object.
2. Our cognitive self-experience.
C. The object itself.
3. Our cognitive constitution itself. 
Accordingly, our experience of the object (B) is structured both by our conception of the object (A) and by the object itself (C). Likewise, our self-experience as knowers (2) is structured both by our cognitive self-conception (1) and by our actual cognitive constitution (3). Hegel's analysis entails that we have no conceptfree empirical knowledge or self-knowledge, and also that we are not trapped within our conceptual schemes! Positively, our experience of the object (B) can correspond with the object itself (C) only if our conception of the object (A) also corresponds with the object itself (C). Likewise, our cognitive self-experience (2) corresponds with our actual cognitive capacities (3) only if our cognitive self-conception (1) also corresponds with our actual cognitive capacities (3). Conversely, insofar as our conception of the object (A) or likewise our cognitive self-conception (1) fail to correspond with their objects (C, 3), we can detect and correct this lack of correspondence through sustained attempts to comprehend our objects $(\mathrm{C}, 3)$ by using our conceptions $(\mathrm{A}, \mathrm{l})$ in our experience of those objects $(\mathrm{B}, 2)$. So doing can inform us whether and how our conceptions $(\mathrm{A}, \mathrm{l})$ can be revised in order to improve their correspondence with their objects $(C, 3)$.

Additionally, our conception of the object (A) and our cognitive self-conception (1) must not merely be consistent, but must support each other. Likewise our experience of the object (B) and our cognitive self-experience (2) must support each other. Finally, our conception of the object (A) must render our cognitive self-experience (2) intelligible, and our cognitive self-conception (1) must render our experience of the object (B) intelligible, thus rendering our experience and our account of it more coherent, comprehensive, and better suited to assessing and justifying our epistemic and other cognitive commitments. Achieving this requires that our conceptions (A) and (1) correspond to their objects (C) and (3). At the broad level of epistemology, where different models of the objects of knowledge require different models of knowledge, this complex of correspondences is a sufficient criterion of the truth of an epistemology.

The nub of Hegel's reply to the trope of circularity is to show that, when assessing or reassessing any piece of justificatory reasoning by re-examining its basic evidence, principles of inference, and its use of these, we can revise, replace, or reaffirm as needed any component and any link among components within the justificatory reasoning in question. Because self-criticism and constructive mutual assessment are both fallible and (fortunately) corrigible, Hegel's account of rational justification is fundamentally fallibilist. Hegel recognized that fallibilism about justification is consistent with realism about the objects of empirical knowledge.

Cognitive justification requires mutual critical assessment because our rational capacities are finite: we lack omniscience and omni-competence and we can only base our judgments on information, principles, evidence, examples, and reasonings we actually use, although any claim we make has implications far exceeding what one person can experience. These manifold implications, together with our predilections to focus on some activities, issues, inquiries, or methods rather than others and the division of cognitive labor this generates, entail that others have information pertaining to the rational assessment and justification or revision of our own judgments which we lack. ${ }^{13}$ 
Part of Hegel's genius is his ability to identify the core principles of philosophical views, to take them absolutely literally, and to state exactly what follows from them. Often what follows is far from obvious; Hegel's statement of these implications can be puzzling. Hegel's point is to prompt us to reflect on what we have implicitly assumed and ascribed to that view which is not officially stated in its principles, but is required for them to appear plausible. Hegel's phenomenological method is designed to induce forms of consciousness to reflect more carefully on their initial principles (their "certainty"); it is likewise designed to induce readers to reflect more carefully on their own understanding, not only of any form of consciousness, but also on their own preferred principles and views. For all of these reasons, the possibility of constructive self-criticism is fundamental to Hegel's entire philosophy, and especially to the Phenomenology. ${ }^{14}$

\subsection{Hegel's introductory anticipation of spirit}

Hegel's internal critique of forms of consciousness is designed to identify both the insights and the oversights of each form of consciousness, so that the oversights can be corrected by successor forms of consciousness which ultimately integrate these insights into an accurate, comprehensive account of human knowing (see below, $\$ 6$ )

Controversy about the integrity of Hegel's Phenomenology requires noting that Hegel planned from the beginning to integrate within the Phenomenology both his "science of the experience of consciousness" and his "phenomenology of spirit," as he indicates in the closing lines of his Introduction and reiterates in "Absolute Knowing. $" 15$

\section{Sense Certainty}

\subsection{The context and aims of "Sense Certainty"}

In "Sense Certainty" Hegel seeks to justify his provisional claim in the Introduction that aconceptual "knowledge by acquaintance" is not humanly possible. ${ }^{16}$ Hegel thus criticizes Concept Empiricism, the view that every meaningful term in a language is either a logical term, a name of a simple sensed quality, or can be exhaustively defined by additive combinations of these two kinds of terms. Hegel's critique addresses both aconceptual knowledge of particulars (naive realism) and of sense data (e.g., Hume's simple impressions of sense or Russell's sense data). More constructively, in "Sense Certainty" Hegel reconstructs and defends Kant's semantics of cognitive reference while liberating this semantics from Kant's transcendental idealism.

"Sense Certainty" divides into five main parts: an introduction (II1-5), three analytical phases (II6-11, 12-14, 15-19), and a conclusion (II20-21). ${ }^{17}$ Phases I and II focus on designating particulars by using tokens of types of demonstrative (indexical) expressions, such as 'this', 'that', 'I'; Phase III focuses on designating particulars by ostensive gestures. The transition from "Sense Certainty" to 
"Perception" is based on combining linguistic expressions with ostensive gestures. Hegel's thesis is: singular semantic reference via tokens of demonstrative terms or via ostensive gestures are mutually interdependent, and only secure singular cognitive reference through conceptually structured determinate thoughts about the designated individual and the spatio-temporal region it occupies. En passant Hegel justifies the distinction between the 'is' of identity and the 'is' predication by reducing their presumed identity to absurdity. Initially Sense Certainty conflates these two senses of 'is'; this conflation is the premise of Hegel's reductio argument against their conflation.

Recent semantic theory has shown that part of the meaning of a token of an indexical type term is that a specific speaker designates a specific item within a determinate region of space and time. ${ }^{18}$ Hegel argues for this thesis, which is the negation of sense certainty. Hegel shows that determining the origin of the relevant reference system (the speaker) and the scope of the spatio-temporal region of the designated particular is possible only by using concepts of 'space', 'spaces', 'time', 'times', 'I', and 'individuation', which can only be properly used by also using concepts of at least some of the designated item's manifest characteristics (properties designated by predicates). Hence neither ostensive designation nor singular cognitive reference are possible on the basis of concept-free "knowledge by acquaintance," i.e., sense certainty.

Sense Certainty maintains that our knowledge of sensed particulars is immediate, direct, and non-conceptual; its "certainty" is that we can and do have such knowledge (PS 63.1-5/M 58). To justify his counter-thesis Hegel must assess Sense Certainty strictly internally. Hence Hegel's main question is whether any object of alleged sense-certain knowledge in fact is and appears "immediately" to Sense Certainty. To be charitable to Sense Certainty, Hegel disregards descriptions or predicates and focuses on tokens of indexical expressions such as 'this', 'now', or 'here', which Sense Certainty uses as logically proper names in Russell's sense.

\subsection{The three phases of "Sense Certainty"}

Hegel's first example of "the now" is "the now is the night" (PS 64.32-33/M 60). Here 'is' purportedly expresses an identity. Hegel suggests that we can assess this first example by preserving it: by daybreak it is false. Hence Sense Certainty cannot grasp a simple truth about spatio-temporal particulars without indexing its claims temporally, as true within some period of time. Sense Certainty maintains only that the object it knows "is" (PS 63.28/M 58). However, Sense Certainty cannot reconcile its unrefined, undifferentiated use of 'is' with its own temporally limited and transitory experiences of particulars. Hence our knowledge of sensed particulars requires having and using concepts of 'time' and of determinable 'times', and analogously 'space' and 'spaces'. Hence any tenable analysis of human knowledge of sensed particulars must admit universal, determinable concepts.

In Phase II, Sense Certainty responds by acknowledging the contextdependence of its use of type and token indexical expressions, but claims that genuine sense certainty lies only within its own cognitive reference to an object: 
The truth of this certainty is in the object as my object, or in my meaning; it is, because $I$ know of it. (PS 66.7-8/M 61)

Sense Certainty thus focuses on any one instance of sense certainty, e.g., "The Here is a tree" (PS 66.17/M 61). Yet someone else claims: "The Here is a House." ${ }^{19}$ Is this a counter-example? Hegel's first point is that the mere sensibility of sense certainty (PS 66.12-13/M 61) cannot distinguish among cognitive subjects. Hegel shows, second, that the term 'I' is not a logically proper name; it too is an indexical expression that can only be used by distinguishing between its type and its tokens, because its tokens can only designate a particular speaker (on a particular occasion of use) through its context-dependent character or role.

In Phase III, Sense Certainty ascribes its previous difficulties to its use of language to export its sense-certain knowledge out of its immediate context by reporting it to others (PS 67.27-30/M 63). It now restricts immediate knowledge to the immediate context in which it grasps any one particular, which can only be pointed out ostensively (PS 67.19-27/M 63). Hegel's key point is that, by itself, no ostensive gesture determines the relevant spatial or temporal scope of what it purportedly designates. Any punctual 'here', 'now', 'this', or 'that' lacks temporal and spatial extension; hence it cannot contain, coincide with, or pick out any spatio-temporal particular. Any such particular can be designated ostensively only by determining the relevant volume of space it occupies during some relevant period of time. However, even an approximate specification of the relevant region of space and period of time requires using concepts of 'time', 'times', 'space', 'spaces', 'I', and 'individuation'. Regarding time, Hegel states:

Pointing out is thus itself the movement which pronounces what the now is in truth, namely a result, or a plurality of nows taken together. (PS 68.18-20, cf. 68.22-29/ M 64)

We can only understand or rightly interpret any use of an ostensive gesture if we understand a presupposed system of spatial and temporal coordinates together with the specification of the spatio-temporal region of the designated individual. Mere sensation, mere sensibility is necessary, though not at all sufficient, for sensory knowledge of any spatio-temporal particular, because sensibility alone can neither identify nor ostensively specify which individual is purportedly known, whenever and wherever it may be known by whomever purports to know it. Hence our knowledge of individual sensory objects is neither immediate nor aconceptual.

In the concluding paragraph of "Sense Certainty" Hegel develops his main point. Defenders of immediate knowledge speak of

the being of outer objects, which can be determined still more precisely as actual, absolutely individual, utterly personal, individual things, none of which has an exact duplicate... (PS 69.35-70.1/M 66)

Hegel notes that such talk cannot specify any concrete particular, because these terms equally describe any and every particular. Augmenting such vague terminol- 
ogy with explicit descriptions, however detailed, cannot solve this problem. However specific, no description by itself determines whether no corresponding individual exists, only one such individual exists, or more than one such individual exists. Which is so is equally a function of the contents of the world. Hence to know any one particular requires both describing it and locating it in space and time. Only through ostensive designation can we ascribe the predicates used in the description to any one, putatively located and known, particular. Hegel thus shows that predication is required for singular cognitive reference to any spatio-temporal particular, and that predication requires singular sensory presentation. Only through predication can anyone specify (even approximately) the relevant spatiotemporal region (putatively) occupied by the object one purports to designate. Only in this way can we determine which spatio-temporal region to designate, in order to grasp this (intended, ostended) individual. ${ }^{20}$ In this way, Hegel demonstrates that "the 'is' of predication" is distinct from "the 'is' of identity," and that predication is fundamental in even the simplest cases of our knowledge of sensed particulars.

\subsection{Anti-skeptical and ontological implications of Hegel's analysis}

Hegel's semantics has an important ontological implication. One main Pyrrhonian trope is that we are incapable of knowing reality because all we experience is changing, variable, relative, and transitory. This inference presumes the Paramenidean conception of truth and being, according to which something is 'true' only if it is constant, unchanging, independent (non-relative), and therefore reliable and trustworthy. If so, we can have no knowledge of truth because everything we experience is transitory. Hegel's semantic point is that any concept can play a legitimate cognitive role only if it is referred to particulars. This holds of the concept 'being' (PS 65.1-19/M 60). However, because particulars and our experiences of them are variable and transitory, the Paramenidean conception of truth and being has no legitimate cognitive use. To presume it does is to suffer from cognitively transcendent illusion. This point has an important ontological implication because it concerns in part how we can legitimately conceive the object(s) of human knowledge and experience. These implications are important to Hegel's subsequent critique of skepticism and also to "Force and Understanding" (below, $\$ 5) .{ }^{21}$

\section{Perception}

\subsection{Hegel's issues and aims in "Perception"}

In "Perception" Hegel confronts an issue central to the Modern "new way of ideas" and to the sense data tradition: How can we perceive any one unitary object amidst the multitude of its (putative) sensed qualities? Hegel seeks to show 
three points: (1) demonstrative and observation terms do not suffice for human knowledge of the world, which also requires the legitimate use of substantive $a$ priori concepts of 'perceptible thing' and 'force'; (2) the relation 'thing/property' cannot be defined, substituted, reduced to, or replaced by the relations 'one/ many', 'whole/part', set membership, or 'ingredient/product'; (3) the a priori concept of the identity of perceptible things integrates two opposed quantitative sub-concepts, 'one' and 'many'. This is characteristic of what Hegel designates as genuine Begriffe (concepts) in contrast to Vorstellungen, that is, to universals which lack this kind of internal integration of counterposed sub-concepts. Hegel associates Vorstellungen with the "abstract, finite understanding" and Begriffe with "concrete, infinite reason." Any one Vorstellung is "limited" or finite because it is qualified by - and its use is inseparable from - its unacknowledged counterpart. The understanding's use of Vorstellungen is limited or "finite" because its use of any one Vorstellung requires implicitly relying upon its contrary. In contrast, Begriffe incorporate two counterposed sub-concepts; hence they are not limited in that way. Hence reason's use of Begriffe is unlimited or "infinite" because Begriffe grasp the counterposed aspects of what it knows and thus knows them truly. $^{22}$

The main target of Hegel's critique in "Perception" is Hume's analysis of "body," that is, of our concept and perceptual knowledge of physical objects and their identity (Treatise 1.4.2-3). The "contradictions" Hume identifies in our belief in physical objects coincide with those Hegel identifies within Perception. Hegel's analysis exploits Hume's failure to account for our concept 'physical object' in accord with his own Concept Empiricism to show that our concept of the identity of perceptible things is a priori.

\subsection{Perception as a form of consciousness}

Once Sense Certainty shows that our use of token-indexical terms requires using universal conceptions ('space', 'spaces', 'time', 'times', 'I', 'thing', and 'individuation'), then descriptive concepts of any kind may be admitted into any relevantly human epistemology. Hence Perception purports to know perceptible objects by describing them with predicates and designating them with token-demonstrative terms. ${ }^{23}$ This includes both 'I' to designate a human cognitive subject and 'object' to designate what is there to be known (PS 71.5-8/M 67), as well as predicates. A universal is variously instantiated, though it cannot be identified with any one nor with any set of its instances, and it contrasts with other such universals and their instances (PS 65.11-13/M 60). Perception is the appropriate and necessary successor to Sense Certainty because its epistemic principles admit the use of such universals, though only such universals, to know particular perceptible objects (PS 71.8-11, cf. 63.4-5/M 67, cf. 58). Hegel's gloss on 'universal' matches Hume's (Treatise, 1.1.7.18).

Hegel notes that the perceived object is itself in this sense a universal because the object combines its "moments," its perceptible qualities, into a unity; the 
object exists only in and through its qualities, though it cannot be identified with or reduced to them. Perception itself counts as universal because it differentiates, distinguishes, and also grasps together these "moments" of the object (PS 71.1416/M 67). Perception regards itself as unessential; the object is essential (PS 71.22-25/M 67). Like Sense Certainty, perceptual consciousness begins by avowing realism.

Hegel notes this contrast between Sense Certainty and Perception:

the sensuous is itself still present [in Perception], but not as it is supposed to be in immediate certainty, as the individual meant; but instead as the universal, or as that which will determine itself as a property. (PS 72.3-6/M 68)

Initially the thing's sensible qualities do not yet count as properties. ${ }^{24}$ This qualification indicates a key issue: properties are not parts or ingredients of things. In order to comprehend a sensible object, we need more than just descriptive concepts and merely quantitative conceptions or designations.

The counterpart to the sensed qualities is "thinghood" (PS 72.23/M 68), Perception's conception of its object. An instance of this conception, i.e. an object, constitutes a "medium" in which various instances of sensed qualities occur. Thus far, this object is a region of space and time within which a plurality of sensible quality instances occur (PS 72.22-26/M 68).

Hegel's discussion seems inadequate to characterize a thing with many properties. This is his point: What exactly are the further conditions or presuppositions of a perceptible thing and of our perceptual knowledge of it? Hegel's initial description corresponds to Modern accounts of the concept of substance. In analogy to Descartes's wax, Hegel considers a grain of salt:

This [bit of] salt is a simple here, and yet manifold as well. It is white, and also tart, also cubically formed, also of a determinate weight, and so forth. (PS 72.26-28/M 68)

The perceived thing has three aspects: (1) the "also" or the "indifferent passive medium" in which its various sensible qualities occur. The passivity and indifference of this "thinghood" provisionally hints at the role causality plays in the identity of perceptible things; this passivity marks an assumption of Hegel's reductio argument. (2) The "properties" collected in the thing are "rather matters." These "matters" are determinate stuffs, analogous to the "heat matter" or "magnetic matter" of contemporaneous physics. This analogy suggests how perceptual consciousness comes to regard the qualities of a thing as independent ingredients. Calling them "matters" stresses that, as ingredients of a thing, the perceived instances of universal qualities are not yet proper to the perceived thing. (3) The "unity" of the thing as one individual, distinct from others and excluding them from its region (PS 73.19-26/M 69).

A form of consciousness is "perceptual" if it conceives its object as a "thing" in the sense just specified. However, this conception does not account for how these three aspects of the object are related, especially in Perception's experience. Perception is aware of the plurality of properties of any possible object of 
perception and recognizes that it must properly combine the various qualities of an object with each other. Accordingly, it regards the object as "self-identical" and acknowledges that it may not properly combine the various qualities of an object when apprehending it (PS 74.1-11/M 70).

Acknowledging this suggests that the alleged passivity of perception is untenable and also suggests the questions noted above: How can we combine a particular group sensory qualities into the perception of some one object? What conception of the object is required for such combination? Perceptual consciousness is aware of the possibility of deception; accordingly, it uses "self-identity" as its criterion of truth. To achieve true knowledge of its object, Perception must preserve the thing's "self-identity" while apprehending its various qualities. Lack of self-identity indicates error.

Initially, perceptual consciousness has only the conceptions 'unity' (numerical identity) and 'plurality' (number) to conceive the identity of perceptible things. Hegel grants that 'identity' can only mean 'numerical identity' ('one and the same as' or ' $=$ '); he aims to show that the concept of numerical identity only provides a tenable conception of the identity of perceptible things in conjunction with an integrated conception of the thing as a single thing with a plurality of characteristics. Such an integrated conception of the thing is not initially admitted by perceptual consciousness; it cannot admit it without rescinding its official cognitive passivity and its Concept Empiricism.

\subsection{The three phases of Perception's self-examination}

"Perception" again divides into five parts: an Introduction (II1-6), three analytical phases (Phase I: II7-8, Phase II: II9-12, Phase III: II13-18), and a summary and conclusion (IT 19-21). ${ }^{25}$

In Phase I Perception begins with a Humean idea: "The object that I take up presents itself as purely one" (PS 74.15-16/M 70; cf. Treatise, 1.4.2.26). Yet Perception is also aware of the plurality of the thing's many sensible qualities (or presumptive properties). Hegel aims to exhibit how its failure to integrate the three aspects of its object (noted above) leads Perception to use its conceptions of unity and plurality to reify the thing's qualities to the point of considering only their merely numerical diversity. Hence Perception is led into error and deception (Täuschung) by its own principles and standards. The deception mentioned in Hegel's subtitle to "Perception," "or the thing and deception," is this: Given Modern philosophical ideas about perception and its objects, we deceive ourselves by believing that we perceive physical objects at all, precisely Hume's conclusion. This is not a problem about indirect, representationalist theories of perception, but of a problem lurking at the core of Modern views of sensory ideas and sense data theories: If all we directly sense are various sensory qualities, how can we identify any one physical object at all?

Because Perception lacks a coherent conception of 'physical object', it conflates the identity of a physical object with purely quantitative unity. Perception thus 
commits itself to reducing the relation 'thing/property' to the relation 'one/ many' (or 'whole/part'). The inadequacy of Perception's conceptions emerges directly in Phase I of its self-examination: In trying to perceive one thing, Perception is led by its strictly quantitative conception of unity to distinguish among the thing's various sensed qualities, identifying each in turn as one (unitary) perceptible object. Hence Perception regards the presumed thing as simply a "medium" in which its various (putative) properties occur (PS 74.34, cf. 72.17-26/M 74, cf. 68 ). This fails to make sense of the unity of the perceived thing; hence the perceptible thing cannot be properly conceived even as a "medium" of its properties. Hence Perception fails to perceive any one thing amidst its (alleged) plurality of properties.

Obviously, something has gone badly wrong. Hegel's point is to make this manifest within Perception. The remedy lies in adopting Locke's view that each sensible quality of a thing enters our mind through our distinct sensory channels as a completely separate, simple, pure, and particular sensory idea (Essay 2.2.1, PS 75.35-39/M 72), a view also found in Hume's account of simple sensory impressions. Perception thus improves its conception of its perception, thus rescinding the belief in the utter passivity of perception by recognizing that perception involves some kind of mental processing.

These revisions are central to Perception's second strategy for sustaining its initial conception of the perceived object. In Phase II Perception divides the locus of the thing's unity and plurality. Initially it regards the perceived thing as unitary, but now ascribes the diversity of its perceived qualities to its own distinct sensory channels. Accordingly, Perception assumes the role of the "universal medium" in which a plurality of perceived qualities occurs, thus preserving Perception's conception that the perceived thing is unitary (PS 75.29-76.3/M 72-3).

The problem now is that any perceptible thing is only some one distinct and determinate thing because $i t$ has a variety of determinate characteristics which distinguish it from other things (and determine which region it occupies). Taking upon itself the diversity of the thing's properties thus violates Perception's initial thesis that it perceives determinate, identifiable, mutually distinct individual things (PS 76.4-23/M 72-3). To correct this error, Perception ascribes singularity to the perceived thing, not as an undifferentiated unity, but as a spatio-temporal region in which a plurality of "free matters" (in contemporary terms, 'tropes') occur. These revisions of Perception's view highlight its thoughtful, reflective, and hence active character. They also indicate that Perception sequentially ascribes unity to the thing and qualitative plurality to itself, and then conversely ascribes unity to itself and qualitative plurality to the perceived thing. Perception thus realizes through its experience that the perceived thing presents itself as unitary thing with a plurality of characteristics. Accordingly, Perception must devise a way of ascribing both of these aspects to the thing it perceives (PS 76.24-39/M 73-4).

In Phase III Perception ascribes both unity and a plurality of characteristics to the perceived object, while avoiding the contradiction between its unity and plurality by isolating them from each other. This it does by ascribing the plurality of the thing's characteristics to its relations (both similarities and differences) 
to other things, while ascribing unity to the thing in its isolation from other things (PS 77.13-32/M 74-7). Resolving the contradiction between the thing's unity and plurality requires granting primacy to one of these two aspects of the unitary, self-identical thing. Hence Perception posits the unity of the thing as essential and regards as inessential the plurality of its characteristics (PS 77.33$78.13 / \mathrm{M} 75){ }^{26}$

This strategy fails because emphasizing the sheer unity of any one perceived thing fails to grasp any one such thing because any perceived thing is essentially a unitary individual. This strategy reduces the concept of perceptible things to mere "thinghood." Any perceptible thing is only perceived, experienced, and identified as a particular individual due to its particular characteristics (by which alone we can specify the region it occupies). Hence the distinction Perception draws between the essential unity of the perceived thing and the unessential diversity of its characteristics proves to be merely nominal, not genuine (PS 78.1479.2/M 75-6).

Hegel concludes that the concept of the identity of perceptible things requires an integrated concept of the internally complex thing, which integrates the quantitative sub-concepts 'unity' and 'plurality'. Hegel shows this by demonstrating that neither the unity of the thing can be understood without the plurality of its properties, nor can the plurality of its properties be understood without the unity of the thing.

This provides the basic point of Hegel's claim that the concept of identity of perceptible things contains an objectively valid contradiction. Michael Wolff has shown that Hegel's view of "dialectical" contradictions neither denies nor violates the law of non-contradiction. Instead, Hegel holds that certain important truths can only (or at least can best) be expressed by using what appears to be a formal contradiction. ${ }^{27}$ In the present case, it can appear - as it did to Hume, and as it must to a concept empiricist - that the two quantitative partial concepts contained in the concept of the identity of perceptible things, namely unity and plurality, contradict each other. In the case of perceptible things and the thing/property relation, this is not the case. On the contrary, both aspects of any perceptible thing are mutually interdependent; there is no unitary perceptible thing without its plurality of properties, and, conversely, there are no properties without a unitary thing which they qualify. Hegel's point can be expressed using a biconditional statement: Something is a perceptible thing if and only if it unifies a plurality of properties - and vice versa, a plurality of qualities are properties if and only if they are unified in some one perceptible thing. An adequate concept of perceptible things integrates the two quantitatively opposed sub-concepts 'unity' and 'plurality'. Only with such an integrated concept of perceptible things can one grasp their identity. ${ }^{28}$

Two important, related points about the activity involved in cognition follow. First, we can perceive things only if we integrate the various sensations they cause in us; this is a cognitive activity on our part. Second, the concept of the identity of perceptible things required to integrate sensations or perceptions is a priori, because it cannot be defined or derived in accord with Concept Empiricism. 


\subsection{The binding problem}

Hegel's central concern with the concept of the identity of perceptible things is philosophically significant. The question of what unites any group of sensations into a percept of any one object arises within each sensory modality, and across our sensory modalities; it arises synchronically within any momentary perception of an object, and diachronically as a problem of integrating successive sensations or percepts of the same object. These questions recur at an intellectual level: How can we recognize various bits of sensory information received through sensation to be bits of information about one and the same object, whether at any one moment or across any period of time? These problems about sensations lurk in the core of the Modern "new way of ideas" and within the sense data tradition, though they were recognized by only three Modern philosophers: Hume, Kant, and Hegel. They have been widely occluded by uncritical appeal to what we "notice." These problems with sensations recur today in neurophysiology of perception as versions of a set of problems now called the 'binding problem', which has only very recently garnered attention from epistemologists. ${ }^{29}$

\section{Force and Understanding}

\subsection{Hegel's ontological revolution in "Force and Understanding"}

Hegel's third chapter, "Force and Understanding," is notoriously obscure. One key issue is this: Hegel identifies a crucial equivocation in the traditional concept of substance, unchallenged from the Greeks up through Kant, concerning two senses of the term 'intrinsic' (or 'internal') used to characterize the properties of individual substances. In one sense a characteristic is 'intrinsic' if it is essential to a substance. In another sense, 'intrinsic' contrasts with 'relational'. In this sense, an 'intrinsic' characteristic is contained solely within the individual substance; it is non-relational. Conflating these two senses of 'intrinsic' generates the standard assumption that relational properties cannot be essential to individual substances - whence the (broadly) "atomistic" orientation of Occidental philosophy, that individuals are ontologically basic, whilst relations are derivative, because they depend on individuals, whereas individuals do not depend on their relations.

Hegel's central theses in "Force and Understanding" are these:

1 Forces are essential to matter, and thus to individual physical substances.

2 Forces are essentially interrelations (i) among the components of individual physical substances and (ii) among interacting individual physical substances.

3 (1) and (2.ii) are proven empirically by Newtonian universal gravitation.

4 The traditional ontological presumption that relational characteristics cannot be essential to individual substances thwarts our understanding causal necessity by making it impossible to conceive (1) and (2.ii) consistently. 
5 Causal necessity can be understood properly only if the traditional conflation of the two senses of 'intrinsic' is rejected, so that we can recognize that relational characteristics can be essential to individual substances.

6 (1) and (2.ii) (and hence also (3) and (4)) can be proven by philosophical argument, in ways attempted in "Force and Understanding."

Thesis (1) is Kant's, though Hegel identified the key defects of Kant's proof and attempts a sound justification of it. Hegel defends thesis (2.i) by arguing that only causal forces and the concept 'cause' enable us to understand the identity of any one perceptible thing amidst its plurality of properties. Thesis (2.ii) marks Hegel's attempt to re-analyze and to justify philosophically Kant's thesis that all causal actions (within space and time) are causal interactions. One might distinguish "forces" as relations from the "powers" that give rise to them. Hegel argues that this distinction is nominal, not real, and is a rich source of misleading reifications. Very briefly, Hegel contends that dispositions cannot be monadic properties because dispositions are partly specified by triggering conditions (roughly, occasioning causes) which pertain to the dispositions of other objects or events. Hegel also contends that treating dispositions as monadic properties rests on conflating the two senses of 'intrinsic' he distinguishes.

\subsection{Newtonian proof of theses (1) and (2.ii)}

Hegel's third thesis is surprising; empiricism has made it a commonplace that no claims about essences can be justified by empirical methods. More surprising is Hegel's claim that Newton developed methods that justify some claims about empirical essences (not that Newton used the term). Still more surprising is that Hegel understood Newtonian methods better than empiricists and appreciated these surprising and significant results. ${ }^{30}$ This is a complex issue, which fortunately may be epitomized briefly by considering Newton's debate with Robert Hooke and Christian Huygens about color and its proper scientific study.

Hooke (1667, 49-56, esp. 54) expressly defended Descartes's theory of light against Newton's. Referring to Hooke's work, Christian Huygens (Anon. 1673) likewise criticized Newton's theory of colors, arguing that yellow and blue are the two fundamental colors. He charged that Newton's account of refrangibility only analyzes an "accident" of light, albeit a "very considerable" one, although refrangibility is not quantitatively uniform in the way Newton's theory requires.

Newton (1673) replied that what appears to be white light can be produced by various combinations of colored light, so that white lights can have different constitutions (ibid., 6088-89). Additionally, the fact that combinations of any two colors of light may appear white cannot prove that any pair of colors are the sole "original" colors of which all other colors are composed (ibid., 6089). Newton then summarily stated his method for investigating the colors of light (ibid., 6090-91); this statement is very revealing for the present topic. Newton first defines 'homogenous' light in terms of its equal refrangibility and 'heterogeneous' 
light in terms of unequal refrangibility of its rays. He then reports finding that light rays differ only in their refrangibility, reflexibility, and color, and that any two sources of light which are the same in any one such regard are also the same in the other two. Newton avoided using metaphysical terms and distinctions such as 'essence' versus 'accident', though he expressly defines the homogeneity of colors of light in explicitly quantitative terms of exactly measured refrangibility and reflexibility. Cassirer (1971, 2:407) follows Bloch (1908, 353-6, 451-2), presenting Newton's view as concerning a "physical essence" of light. ${ }^{31}$ Newton avoids such terms. However, Newton's concise statement of his method plainly indicates that the only qualities or characteristics of light subject to scientific investigation and comprehension are precisely quantifiable, and he criticized as "impracticable" Huygens's methods for the very difficult task of measuring these quantities (ibid., 6091). As Bloch notes, Newton reiterates these quantitative methods and their use for analyzing light in Query 31 of the Opticks. ${ }^{32}$

At first glance Hooke's and Huygens's replies to Newton's theory of colors, and his reply to them, may look like convinced advocates reasserting their views in the face of opposition because they disagree about whether or how to quantify physical inquiry and whether only to count as physical science an inquiry which provides exact quantification. Hence this scientific disagreement may appear to be yet another example of inevitable petitio principii due to fundamental disagreement about relevant criteria of justification, as discussed in Hegel's Introduction. This issue about criteria of justification bears on Newton's Rule Four of philosophizing:

In experimental philosophy, propositions gathered from phenomena by induction should be considered either exactly or very nearly true notwithstanding any contrary hypotheses, until yet other phenomena make such propositions either more exact or liable to exceptions. (Newton 1999, 796)

Newton adds: "This rule should be followed so that arguments based on induction may not nullified by hypotheses" (ibid.). Harper (forthcoming) shows that Newton's Rule Four is anti-Cartesian because it rules out as scientifically illegitimate merely logically possible alternative 'hypotheses' and because it requires any genuinely scientific competing hypothesis to have, not merely empirical evidence, but sufficient evidence and precision either to make an accepted scientific hypothesis "more exact" or to qualify or restrict it by demonstrating actual "exceptions." Newton's Rule Four thus rejects the deductivist justificatory ideal of scientia, and with it mere logical possibility as a sufficient basis for a proposition to state either a scientific hypothesis or a scientifically legitimate objection to an hypothesis.

The anti-Cartesianism of Newton's Rule Four may appear simply to repudiate rationalism and to advocate empiricism about natural science. Empiricists generally tend to regard physical theories as involving only maximally precise measurements and precisely formulated mathematical descriptions of natural regularities, though without commitment to any specific causal ontology that generates measured regularities. Even the non-empiricist Ernst Cassirer mistook the Newtonian method of John Keill in this way. ${ }^{33}$ 
However, Harper shows that this deflationary view seriously misunderstands Newton's methods and achievement. Newton devised analytical methods for using the phenomena of planetary motions to measure with increasing precision the strength of the gravitational force produced by each planet. This increasing precision results from iterative use of the same explanatory resources to progressively eliminate various idealizations used in the initial approximations. The progressive increase in accuracy required by Newton's standards of theoretical adequacy significantly exceeds the requirements of other accounts of theoretical adequacy current among philosophers of science. Significantly, Newton's standards of theoretical adequacy apply to the shift from Newtonian to Einsteinian mechanics, and, on the basis of the relevant evidence, favor Einsteinian mechanics. This is only the briefest word about the method and aim of Newton's gravitational theory, which requires a stout book (such as Harper's tour de force) to explain.

In "Force and Understanding" Hegel argues that Newtonian gravitational theory, as revised on the basis of analysis (calculus), provides the sole and sufficient basis ascribing gravity as an essential characteristic to matter. ${ }^{34}$ In this regard, Hegel contends that natural science can identify the essences of natural objects and events, where these essences are physical or material or, in a word, natural rather than supernatural or metaphysical. In this regard, Hegel argues on behalf of Newton in his debate, for example, with Hooke and Huygens about color and its scientific investigation. Hegel does this by justifying Newton's Rule Four by exploiting an important consequence his semantics of cognitive reference defended in "Sense Certainty."

\subsection{Hegel's semantic support for Newton's Rule Four}

Kant's rejection of pre-Critical metaphysics is rooted in his cognitive semantics. Kant's cognitive semantics grants that a priori concepts can have content or meaning unto themselves, but also requires that determinate, genuinely cognitive content for any proposition or judgment using a priori concepts requires another constituent of meaning provided by referring those propositions or judgments to spatio-temporally identified (located) particulars. The semantic requirement of reference to particulars thus achieves the empiricist aim of restricting our cognitive claims to the realm of what we can experience, while dispensing with untenable verificationist theories of meaning.

Hegel recognized that Kant's semantics of cognitive reference also has important implications for judgments or propositions formulated with empirical concepts: to have determinate and cognitively legitimate meaning, they too require being referred to spatio-temporally identified (located) particulars. Voilà! The direct implication is that the mere logical consistency of a presumed alternative to a natural-scientific theory or hypothesis does not suffice for its cognitive legitimacy! To be cognitively legitimate, an alternative must also be referred (and not merely 
be "referable in principle") to spatio-temporally identified (located) particulars. Hegel's cognitive semantics thus rules out the deductivist model of scientia for empirical justification, and so rules out mere logical possibilities as counterexamples to empirical - or to philosophical - claims.

Hegel's pro-Newtonian cognitive semantic is important for understanding one of the most important and puzzling statements in "Force and Understanding." Hegel recognized that Newton's theory provides adequate grounds for ascribing gravitational force directly to matter; matter is "essentially heavy" in the sense that material bodies inherently tend - they gravitate - towards one another (Enc. $\$ \$ 262,269)$. So far as logical or metaphysical necessities are concerned, natural phenomena could instantiate any mathematical function whatsoever, various mathematical functions on different occasions, or no such function at all. However, the fact that a natural phenomenon regularly exhibits a precise mathematical function indicates, as nothing else can, that something in that phenomenon is structured in accord with that mathematical function. That "something" is the causal structure of the phenomenon, the structure of the basic causal powers or disposition(s) which generate the phenomenon in question. Bringing various specific phenomena under a common general law (not merely a common mathematical function) formulated in terms of common explanatory factors (such as gravity) shows that these phenomena are interrelated; they are not mutually independent, self-sufficient objects or events (PS 92.23-26/M 91-2). Hence the concepts 'law-like relation' and 'force' require interdefined factors into which the phenomena can be analyzed (PS 93.7-94.28/M 92-4). In sum:

the force is constituted exactly like the law. (PS 95.12-13/M 95, original emphasis)

This statement indicates Hegel's concern to show that adequate scientific explanation provides sufficient basis for determining the essential, and essentially causal, characteristics of natural objects and events. Comprehending their essential characteristics provides explanatory insight. ${ }^{35}$

The standard objection to this claim is that the "underlying" causal factors giving rise to any natural regularity, however precisely measured and described mathematically, may be structured very differently than is stated or suggested by our formulation of natural laws. This is Cartesianism speaking, pure and simple! Yes, there's a "logical" gap between any statement of a law of nature and whatever generates the regularity specified by that statement. However, this logical gap does not entail a cognitive gap between a well-grounded causal law and the causal structure generating the regular natural phenomenon described by that law. To suppose that a "logical" gap entails a cognitive gap un-Critically presupposes the pre-Newtonian, Cartesian deductivist ideal of justification as scientia. To the contrary, any discrepancies between our best-justified causal laws and the actual causal structure(s) of natural phenomena can only be discovered by extended scientific investigation. Deductivist cavils of empiricist philosophers are, Hegel's anti-Cartesian cognitive semantics shows, cognitively transcendent idle speculations. 


\subsection{Hegel's transcendental support for his cognitive semantics}

These consequences place a considerable burden of proof on Hegel's cognitive semantics. "Sense Certainty" provides powerful - I have argued elsewhere, sound - justification of Hegel's cognitive semantics. Hegel's Phenomenology also purports to offer a genuinely transcendental proof of realism which supports his cognitive semantics. By 1802 Hegel recognized that Kant's transcendental idealism was subject to internal critique which shows that genuinely transcendental proofs do not require transcendental idealism, and that one such proof demonstrates mental content externalism, the thesis that at least some of our 'mental' contents can only be defined and understood in terms of extra-mental objects or events. Indeed, Hegel argues that we human beings cannot be self-conscious and cannot be aware of any 'mental' contents unless we are conscious of and identify at least some features of objects or events within our surroundings, which are what they are regardless of what we say, think, or believe about them. ${ }^{36}$ Hegel made these discoveries before writing the Phenomenology, and incorporated them into it.

Very briefly, Hegel aims in the first three chapters, "Consciousness," to prove that we can be conscious of objects in the world around us only if we are selfconscious. In the second main section, "Self-Consciousness," Hegel aims to prove that we can be self-conscious only if we are conscious of objects in the world around us. In this way, Hegel's Phenomenology aims to re-establish the conclusion to Kant's "Refutation of Idealism," though without appeal to transcendental idealism. If Hegel can establish these claims, then he provides genuinely transcendental proof of realism which also supports his cognitive semantics, which is required for our determinate consciousness of any particulars at all. The implication for Newton's Rule Four is that Hegel's cognitive semantics rules any alleged hypothesis lacking supporting evidence out of legitimate cognitive, hence also scientific, bounds. By establishing that positive empirical support is required for any determinate, cognitively significant hypothesis, Hegel's cognitive semantics unloads much of the justificatory onus from Newton's Rule Four, which (in view of Hegel's cognitive semantics) very reasonably requires that to be a legitimate counterhypothesis, an hypothesis must have sufficient empirical support to render an established hypothesis either "more exact" or to restrict its scope by identifying "exceptions" to it. ${ }^{37}$

\section{5 "Force and Understanding" in brief}

"Force and Understanding" is ungainly, though it too has an introduction (II4), three analytical phases (I: II5-10, II: II11-17, III: II18-30), and conclusion (IT32-34)..$^{38}$ Whereas all three phases of Perception sought to isolate the unity of the thing from the plurality of its characteristics by reifying them into distinct, mutually independent aspects of the perceived thing, all three phases of 
Understanding seek to isolate the relatta of causal relations by reifying them into distinct, mutually independent entities.

By the end of "Perception," Perception became "perceptual understanding" by developing and using an unconditioned universal concept, that is, a concept integrating two counterposed sub-concepts (PS 79.24/M 77). The main problem confronting Understanding (as a form of consciousness) is that it does not grasp how the unity of the thing is integrated with its plurality of properties (PS 83.4-6/ M 80). The general solution to this problem, in Phase $I$, is to introduce the concept of force. So doing is warranted by the reciprocal relations between any one perceptible thing and its plurality of properties, and by how these reciprocal relations are manifest in relations among perceived particulars (PS 83.31-85.8/M 81-3). Understanding distinguishes between "repressed" and "expressed" (or potential and actual) force and ascribes potential forces to mutually independent particulars. This invokes a substantival (rather than relational) conception of force, which includes the asymmetrical or unilateral notions of force inherent in preNewtonian mechanical models of causality (PS 85.9-13/M 83). The sharp contrast thus drawn between (allegedly) "real" potential force and the manifest appearances of its actualization requires that any individual force is triggered into expressing itself by other, intervening objects which "solicit" that force into activity (PS 85.9-30/M 83).

The term "solicitation" was used by both Leibniz and Kant in their dynamic theories. However, the target of Hegel's critique is what Herder made of their views. Herder advocated the thesis that "things" are the unsensed causes of our sensory experience, a notion found in Protagoras, Pyrho, Sextus Empricus, Locke, Kant and in some of Putnam's arguments for 'internal realism' ${ }^{39}$ Herder sought to justify this thesis, or at least to make it unassailable by advocates of science, by reifying the aspects of causal interaction into distinct, intervening entities, so that (purportedly) we only can observe the manifestations of any real force, though we cannot identify either its locus or its genuine, intrinsic character. Herder's antiscientific skepticism welcomed the infinite regress apparently generated by positing forces of solicitation, which themselves require solicitation by yet other forces of solicitation, ad infinitum.

Briefly, Hegel's analysis of force responds to this view by showing that introducing reified "solicitations" (so to speak) does not avoid the original relations of force-interaction for which they purportedly substitute; instead, each "solicitationevent" (so to speak) requires causal interaction (that is, causal relation) between two particulars, including, ex bypothesi, "solicitations." Hence multiplying particulars to avoid analyzing causal interactions by introducing "solicitations" fails to come to terms with the original phenomenon of causal interaction which this line of objection presupposes rather than eliminates. This failure to eliminate basic causal interaction between particulars underscores that forces essentially consist in causal interactions. Causal interaction involves (roughly) two or more particulars triggering each other's potentials (dispositions) to manifest themselves actively. This requires that each particular is both unitary and that it generates a plurality 
of active, occurrent, relational qualities (PS 86.12-87.8/M 84-5). Hegel's interim result is: forces are actual only in causal interactions among particulars. Unto themselves, dispositions as such are only potentially forces; to regard them as 'potential forces' is an unwarranted reification (PS 87.9-39/M 85-6).

Not yet prepared to concede Hegel's interim conclusion, in Phase II (III12-18) Understanding ascribes unitary, intrinsic force-centers to a supersensible realm and ascribes their manifold manifestations to the realm of appearances (PS 88.1-89.3/ M 86-8). This universalizes Herder's view. The object "in itself" is supersensible; "for us" are only its (purportedly causal) manifestations. Though clearly alluding to Kant's "thing in itself," Hegel aims to show that no distinction between things "for us" and things "in themselves" contributes to understanding forces, regardless of whether this distinction is drawn empirically or transcendentally.

The realm of appearance thus intervenes between us and things in themselves; appearances are their sole effects on us, and they provide our sole access to real, supersensible objects (PS 89.4-15/M 87-8). Hegel first points out that this supersensible realm is our own projection. The contrast between it and appearances is made in such a way that in principle appearances can provide no basis for any determinate ascription of characteristics to (purported) supersensible objects. Hence our utter ignorance of supersensible entities shows nothing about such entities, nor about the limits of human cognition, but only how this distinction between appearances and the supersensible has been devised by its advocates (PS 89.16-90.7/M 88-9). Thus distinguishing broadly (whether empirically or transcendentally) between the realms of appearance and of things in themselves contributes nothing to comprehending manifest causal interactions. Second, Hegel notes, our only possible basis for supposing there is a supersensible realm, or that it is characterized in one way rather than another, is the realm of appearances. However, the distinction between them is devised to block any determinate inference from appearances to the supersensible.

To remedy this situation, in Phase III (II19-31) Understanding seizes upon the determinate specification of causal forces in the form of "laws of force" (PS 90.32-91.26/M 89-91). Causal laws now provide a determinate content for the Understanding, which posits these laws in a peaceful supersensible realm, in contrast to the plethora of ceaseless changes among appearances governed by these laws (PS91.27-30/M 90-1). The problem with distinguishing in this way between a supersensible realm of causal laws and the ceaseless changes manifest in nature is that appearances are essential to the specific manifestations of causal laws because any causal law manifests itself differently in different conditions (PS 91.33-35/M 91), now called 'triggering conditions'. Accommodating these conditions multiplies particular causal laws, which must then be explanatorily integrated under more general laws, such as Newton's law of universal gravitation (PS 92.8-10/M 91). Hegel claims Newton's law is

of great importance insofar as it is directed against the thoughtless representation (Vorstellung), according to which everything presents itself in the form of contingency, and determinateness has the form of sensible self-sufficiency. (PS 92.23-25/ M 91) 
The "form of sensible self-sufficiency" Hegel here criticizes is the presumptive ontological atomism according to which spatio-temporal particulars are mutually independent, hence self-sufficient unto themselves and only contingently related to one another. Hegel here claims that Newtonian gravitational theory belies this apparently obvious, commonsense atomism by showing that physical particulars are fundamentally interrelated by gravitational forces which are intrinsic to matter even though they are relational, though his statement of this key conclusion is provisional. ${ }^{40}$

The Understanding now ascribes all particular laws to the realm of appearances while the pure form of law, that "everything exhibits a constant difference to everything else," is ascribed to the supersensible realm (PS 92.26-95.17/M 92-5). This approach generates the "covering law" or "hypothetico-deductive" model of scientific explanation, which Hegel deftly shows is circular and explanatorily vacuous (PS 94.26-95.24/M 94). The Understanding thus loses its presumed grasp of the very happening of events it proposed to comprehend with causal laws (PS 95.24-39/M 95). Hence the Understanding modifies its account of the supersensible realm by introducing into it a "law of pure change" and explaining the apparent world of manifest change on the basis of a very different supersensible realm consisting in the opposites of all apparent, occurrent qualities. For example, manifest sweetness is generated by supersensible sourness, manifest black is generated by supersensible white, etc. Hence this very different version of the supersensible world is the inversion of the manifest world of appearances (PS 96.1-97.35/M 95-8). Understanding's strategy thus attempts to analyze causal necessity in terms of logical exclusion relations. (This view in some regards resembles Brandom's inferentialism.)

Philosophically, this new supersensible world is equally a perversion of the realm of appearances and of causal concepts altogether. Now that the Understanding identifies relevant contrasts between positive and negative electricity, or the oxygen and hydrogen poles of an electrolytic cell, or the two poles of a magnet, its key distinctions, 'inner/outer' and 'appearance/supersensible', are simply useless because the polar phenomena it identifies cannot be justifiably distributed among any two substances, whether they are distinguished numerically or metaphysically, not at least without reverting to the reifying strategies of Perception critically rejected previously. Such a supersensible world is merely a projected converse sensible world, which in principle cannot itself be sensed at all (PS 97.39-98.10/M 98).

Once these atomizing and reifying tendencies collapse, we can appreciate that what produces a North magnetic pole produces the South pole of the same magnet, and likewise for other polar phenomena, which Hegel thinks is typical for causal relations: the terms of these relations are mutually interdefined in ways that reflect the interdependent identity conditions of particulars which stand in causal relations. Hegel thinks this also holds for space and time and for distance and velocity, which are interdefined as aspects of any gravitational motion (PS 99.15-21/M 99). If Hegel describes this kind of mutual interrelation in terms of "contradiction" (PS 98.33/M 99), this is because such relations must appear to 
any atomist as contradictions, in part due to the once-pervasive assumption that the logical law of identity entails an atomistic ontology. This assumption is false, and Hegel's use of the term "contradiction" does not violate the logical law of non-contradiction. ${ }^{41}$

In sum, Hegel's thesis that the causal characteristics of things are central to their identity conditions, and that their identity conditions are mutually interdefined due to their essential causal relations, is justified by exhibiting the futility of atomistic, reifying strategies to avoid this conclusion in the face of Newtonian universal gravitation. ${ }^{42}$ Furthermore, the relevant interdefined aspects of causal phenomena, Hegel contends, cannot be specified by armchair philosophical reflection, but only by empirical, natural-scientific investigation of causal phenomena. ${ }^{43}$ Natural science is thus essential (necessary, if not fully sufficient) to identifying and justifying the relevant conceptual distinctions.

\section{Hegel's Epistemological Analysis in the Phenomenology of Spirit}

\subsection{One unifying armature of the Phenomenology of Spirit: epistemology}

Hegel's overarching epistemological analysis in the Phenomenology may be summarized briefly. In "Sense-Certainty" Hegel argues by reductio ad absurdum against naive realism, that our conceptions of 'time', 'times', 'space', 'spaces', 'I', and 'individuation' are a priori because they are necessary for identifying and knowing any particular object or event, on the basis of which alone we can learn, define, or use any empirical concept. Hence these concepts are presupposed rather than defined by Concept Empiricism. Hegel further argues that localizing a particular object or event in space and time and ascribing characteristics to it are mutually complementary components of predication, which is required for singular cognitive reference, which requires singular sensory presentation. Hence aconceptual "knowledge by acquaintance" or sense certainty is humanly impossible.

In "Perception" Hegel further argues against Concept Empiricism that observation terms plus logic do not suffice for empirical knowledge because our concept 'physical object' cannot be defined in accord with Concept Empiricism, it is a priori and is necessary for identifying and knowing any particular object or event. More specifically, Hegel argues that the 'thing/property' relation cannot be reduced to or adequately analyzed in terms of the relations 'one/many', 'whole/ part', set membership, or 'ingredient/product' because the concept of the identity of a perceptible thing integrates the two opposed quantitative sub-concepts 'unity' and 'plurality'.

In "Force and Understanding" Hegel argues that our conception of 'cause' is pure a priori and is necessary for identifying and knowing any object or event; 
that statements of laws of nature are conceptual and express actual structures of nature; that the identity conditions of spatio-temporal particulars are mutually interdefined on the basis of their essential causal relations; and that our consciousness of objects is possible only if we are self-conscious.

In the introductory discussion to "Self-Consciousness," Hegel argues that biological needs involve classification and thus entail realism about objects meeting those needs. In "Lord and Bondsman" Hegel argues that the natural world is not constituted by will, a second important lesson in realism. In "The Freedom of Self-consciousness," Hegel argues that the contents of consciousness are derived from a public world, and that self-consciousness is humanly possible only if we are conscious of mind-independent objects. The first two major sections of Hegel's Phenomenology, "Consciousness" and "Self-consciousness," thus replace Kant's "objective" Deduction of the Pure Concepts of the Understanding, his proof that we can and must use a priori concepts in legitimate cognitive judgments about spatio-temporal objects and events. Hegel's justification of Kant's conclusion to his "Refutation of Idealism," that "inner experience in general is only possible through outer experience in general" (CPR B277, cf. B275), does not rely on Kant's transcendental idealism.

In "The Certainty and Truth of Reason," Hegel argues that classificatory thought presupposes natural structures in the world which must be discovered (rather than created or legislated) by us. In "Observing Reason" he argues that classificatory, categorial thought is not merely a natural phenomenon. In the two subsequent sections of "Reason," "The Actualization of Rational SelfConsciousness by Itself" and "Individuality That Is Real in and for Itself," Hegel argues that categorial thought is not merely an individual phenomenon. The implicit epistemological result of these reductio arguments in "Reason" is that individual thinkers are who they are only within a natural and social context. Hegel's express result is that each of the preceding sections of the Phenomenology has analyzed different aspects of one concrete social whole, including its natural environment.

In "Spirit" Hegel analyses the tension and interaction between individual reasoning and customary practice. In "True Spirit, Ethics," Hegel argues that categorial and justificatory thought are not constituted or justified merely by custom or fiat. In "Self-Alienated Spirit" and in "Self-Certain Spirit, Morality," Hegel argues that categorial and justificatory thought are not corrigible merely a priori (and so individualistically). In the concluding section of "Spirit," "Evil and Forgiveness," Hegel argues that the corrigibility of categorial and justificatory thought is a social phenomenon, and yet is consistent with realism about the objects of human knowledge (and strict objectivity about practical norms).

This is precisely the point reached by the two moral judges Hegel analyses in "Evil and Forgiveness." Here an agent and an observer dispute who has proper, legitimate authority to judge the agent's behavior. After struggling over this issue in various ways, these two moral judges finally each rescind the presumed supremacy and self-sufficiency of their own antecedent convictions 
and standpoint, and recognize that they are both equally fallible and equally competent to judge particular acts (whether their own or others'), and that each of them requires the other's assessment in order to scrutinize and thereby to assess and to justify his or her own judgment regarding any particular act. ${ }^{44}$ With this insight, the two judges become reconciled to each other, and to the fundamentally social dimensions of genuine rational, justificatory judgment. Expressly, this is the first instance of genuine mutual recognition in Hegel's Phenomenology of Spirit. ${ }^{45}$

Significantly, Hegel also indicates that this achievement is the advent of "absolute spirit":

The word of reconciliation [between the two judges] is the extant spirit, which beholds the pure knowledge of itself as universal essence in its opposite, in the pure knowledge of itself as the absolute individuality existing in itself - a reciprocal recognition which is absolute spirit. (PS 361.22-25/M 408)

The "universal essence" mentioned here is the knowledge, principles, practices, and context of action (both social and natural) shared within a social group. All of this is required, and understanding of all this is required, in order rationally to judge that "I judge," and not merely to utter the words "I judge," thereby only feigning rationality. ${ }^{46}$

In "Religion" Hegel contends (very roughly) that the history of religion is the initial, allegorical, premature recognition of the social and historical bases of our categorial comprehension of the world. These three major sections of the Phenomenology, "Reason," "Spirit," and "Religion," thus form Hegel's replacement for Kant's "subjective" Deduction of the Categories, which explains how we are able to make the kinds of legitimate, justifiable judgments analyzed in his prior Objective Deduction (in "Consciousness" and "Self-Consciousness"), which shows that we can make such judgments, because if we couldn't, we could not be self-conscious.

Hegel draws these strands together in his concluding chapter, "Absolute Knowing," in which he highlights how the Phenomenology provides us with reflective conceptual comprehension of the social and historical bases of our categorial comprehension of the world. This result is a sophisticated version of sociohistorically based epistemological realism. ${ }^{47}$

\subsection{The structure of Hegel's epistemological argument in the Phenomenology of Spirit}

The structure of Hegel's epistemological analysis is easily mapped onto Hegel's Table of Contents. So doing provides a useful summary of Hegel's epistemology in the Phenomenology and may also help orient the reader for the subsequent chapters of this collective commentary; see below, pp. 28-29. 


\section{Conclusion}

Like other philosophers, epistemologists must heed the 'Kiss principle': Keep it simple, stupid. Yet epistemologists have not often heeded Einstein's explication of Ockham's Razor: “Everything must be made as simple as possible, but not any simpler." 48 The scope, issues, and content of Hegel's epistemological analysis in the Phenomenology are vast and unparalleled. If Hegel is right that both Concept Empiricism and transcendental idealism are false, that the Dilemma of the Criterion puts paid to both coherentism and foundationalism (either as scientia or historia), that epistemology must heed our cognitive finitude and our mutual interdependence as cognizant beings, that epistemology is closely linked to natural science, and that (to avoid petitio principii and to solve the Dilemma) positive theses must be justified by strictly internal critique of all relevant alternatives, then an epistemological project like Hegel's Phenomenology must be undertaken. ${ }^{49}$

It is a major contribution to epistemology to identify, as Hegel does in his first three chapters, a previously unnoticed though central link between Pyrrhonian and Cartesian skepticism also shared by empiricist objections to causal realism within philosophy of science: In principle, none of their key premises or hypotheses have legitimate cognitive significance because none of them are referred to identified particulars located in space and time. The Paramenidean conception of changeless truth and being lacks such referrability in principle, Cartesian skeptical hypotheses are designed to lack such referrability, while empiricist objections to causal realism based on mere logical possibilities of justificatory gaps or alternative causal scenarios all lack such referrability. These results underlie Hegel's subsequent analysis of how skepticism (and ultimately relativism, too), in whatever forms, involves fundamental alienation from our natural and social world rooted in self-alienation from human knowledge. Hegel considers these issues directly in the second part of "Self-Consciousness," they are at least implicit in "Observing Reason," and they come to the fore in "Self-Alienated Culture." This theme links Hegel's epistemology to his ensuing Kulturkritik.

A second major contribution to epistemology is to solve the Dilemma of the Criterion; a third is to show that genuine transcendental proofs can be provided without appeal to Kant's transcendental idealism and can be used to justify realism, in part by justifying mental content externalism. Hegel's fourth contribution is to support Newton's Rule Four with his cognitive semantics. Finally, lingering suspicion of causal notions among philosophers of science because causal relations cannot be "perceived" - is a relic of Hume's concept empiricism and theory of perception. Hegel's trenchant critique of these two views shows how ill founded such suspicions are. Notorious allegations about Hegel's neglect of epistemology or misunderstanding of natural science reflect ignorance of Hegel's actual views; such allegations do not survive scrutiny. Hegel's epistemology is more vital today than ever; it behooves us to mine its philosophical riches. ${ }^{51}$ 
Contents of Hegel's Phenomenology of Spirit

A $\quad$ Sense-Certainty; The 'this' and meaning.
II Perception; The thing and deception.

CONSCIOUSNESS

III Force \& Understanding; Appearance \& the super-sensible world.

\begin{tabular}{llll}
\hline B & IV & The Truth of Self-Certainty [Life \& Desire]. \\
& IVA & Self-Sufficiency er Self-Insufficiency of Self-conscionsness; Mastery er Servitude. \\
SELF-CONSCIOUSNESS & IVB & Freedom of & a Stoicism. \\
& & Self-Consciousness. & b Skepticism. \\
& & c Unhappy Consciousness.
\end{tabular}

\begin{tabular}{|c|c|c|c|c|}
\hline $\mathrm{C} / \mathrm{AA} / \mathrm{V}$ & Cert & ity \& Truth of Reas & & \\
\hline & VA & Observing Reason. & & $\begin{array}{l}\text { Observation of Nature. } \\
\text { Observation of Self-consciousness I: Logic \& } \\
\text { Psychology. } \\
\text { Observation of Self-consciousness II: } \\
\text { Physiognomy \& Phrenology. }\end{array}$ \\
\hline REASON & $\mathrm{VB}$ & $\begin{array}{l}\text { The Actualization } \\
\text { of Rational Self- } \\
\text { consciousness } \\
\text { through Itself. }\end{array}$ & $\begin{array}{l}\mathrm{a} \\
\mathrm{b} \\
\mathrm{c}\end{array}$ & $\begin{array}{l}\text { Pleasure \& Necessity. } \\
\text { Law of the Heart \& the Insanity of Conceit. } \\
\text { Virtue \& the Way of the World. }\end{array}$ \\
\hline & $\mathrm{VC}$ & $\begin{array}{l}\text { Individuality } \\
\text { which is Real In } \\
\text { \& For Itself. }\end{array}$ & $\begin{array}{l}\mathrm{a} \\
\mathrm{b} \\
\mathrm{c}\end{array}$ & $\begin{array}{l}\text { The Animal Kingdom of the Spirit \& Humbug. } \\
\text { Legislative Reason. } \\
\text { Law-testing Reason. }\end{array}$ \\
\hline
\end{tabular}

$\mathrm{C} / \mathrm{BB} / \mathrm{VI}$

a The Ethical World: Human \& divine law; man \& woman.

VIA True Spirit; Ethics. b Ethical Action: Human \& divine knowledge, guilt \& fate.

c Legal Status.

a The world of self-alienated spirit.

i Enculturation \& its realm of actuality.

VIB Self-Alienated ii Faith \& pure insight.

Spirit; b The enlightenment.

IMMEDIATE SPIRIT

Enculturation.

i The enlightenment vs. superstition.

ii The truth of the enlightenment.

c Absolute freedom \& the terror.

a The Moral Worldview.

b Dissemblance.

VIC Self-Certain Spirit; c Conscience; the beautiful soul, evil \& its Morality. $\quad$ forgiveness.

\begin{tabular}{llll}
\hline C/CC/VII & & a & The Light-being. \\
& VIIA Natural Religion. & b & Plants \& Animals. \\
& & c The Artificer. \\
\hline & & a & The Abstract Work of Art. \\
RELIGION & Art-Religion. & b The Living Work of Art. & c The Spiritual Work of Art. \\
\cline { 2 - 4 } & VIIC & Manifest Religion. \\
\hline
\end{tabular}




\title{
Argument in the Phenomenology of Spirit
}

\author{
Main Epistemological Theses Hegel Defends in the Phenomenology ${ }^{52}$
}

t.s.: (1) Our conceptions of 'time', 'times', 'space', 'spaces', 'I', and 'individuation' are pure a priori and

(2) are necessary for identifying and knowing any particular object or event.

t.s.: (1) Observation terms alone do not suffice for empirical knowledge; (2) our conception 'physical object' is pure a priori, (3) it integrates the two opposed sub-concepts 'unity' and 'plurality' and (4) it is necessary for identifying and knowing any particular object or event.

t.s.: (1) We can only properly conceive causal forces by recognizing that essential properties can be relational; (2) Statements of laws of nature are conceptual and express actual structures of nature; (3) Our consciousness of objects is possible only if we're self-conscious.

t.s.: Biological needs involve classification, which entails realism about objects meeting those needs.

t.s.: The natural world is not constituted at will: a lesson in realism.

t.s.: (1) The contents of consciousness are derived from a public world;

(2) Self-consciousness is possible only if we're conscious of objects.

$($ Consciousness + Self-Consciousness $=$ Hegel's replacement for Kant's Objective Deduction of the Categories.)

t.s.: Classificatory thought presupposes natural structures in the world which must and can be discovered.
t.s.: Classificatory, categorial thought is not merely a natural phenomenon.
t.s.: Categorial and justificatory thought are not merely individual phenomena.
$\begin{aligned} & \text { (Implicit results of Reason: (1) Individual thinkers are who they are only within a natural and social } \\ & \text { context; (2) Each of the preceding sections has analyzed different aspects of one concrete social } \\ & \text { whole.) }\end{aligned}$

t.s.: Neither custom nor fiat suffice to constitute genuine categorial or justificatory thought.

(Analysis of the tension and interaction between individual reasoning and customary practice runs throughout 'Immediate Spirit'.)

t.s.: Categorial and justificatory thought are not corrigible merely a priori.

t.s.: Kant's individualist theory of moral judgment and action is inadequate.

t.s.: (1) Individual judgment, required for rational justification of all kinds, is social, because we can only judge fully rationally by recognizing our own fallibility, so that we require the constructive criticism of others (and they require ours) in order to assess and to sustain our own rational judgment; hence (2) The corrigibility of categorial and justificatory thought is a social phenomenon.

t.s.: Religion is the initial, allegorical, premature, collective recognition of the social and historical bases of categorial comprehension of the world.

$($ Reason + Spirit + Religion $=$ Hegel's socio-historical replacement for Kant's 'Subjective Deduction' of the Categories.)

t.s.: Through the Phenomenology, we gain reflective conceptual comprehension of the social and historical bases of categorial comprehension of the world (= socio-historically grounded epistemological realism). 


\section{Notes}

1 Central issues from Hegel's Preface are discussed below, chapter 13. $-E d$.

2 PS 19.12-23, 19.34-20.4/M 11, 12.

3 This is how Hegel initially defines 'the absolute' (PS 53.1-2/M 46). Note: Single quotes are used to mention terms which are not used in their present context.

4 All translations are by the author.

5 'Question-begging' or 'begging the question' name the logical fallacy of petitio principii.

6 Omitted is intuitionism in logic or mathematics.

7 The problem of assessing and resolving conflicting assertions raises key issues about the normative adequacy of individual rational judgment; it recurs throughout the Phenomenology, e.g., in "Lord and Bondsman," "Skepticism," "Observing Reason," "The Law of the Heart," "The Animal Kingdom of the Spirit," Antigone vs. Creon, Enlightenment vs. Faith, and "Conscience." See below, pp. 2-3, 17-18, 25-26, 37-53 passim, 60-64, 178-80, 229-30, 239-40. - Ed.

8 BonJour (1997, 14-15). Unwittingly, BonJour concedes the very point already made by von Juhos and Ayer against Hempel; see Westphal (1989, 56-7).

9 Common from Aristotle through the Modern period, this distinction remains influential today, as is evident from the extent to which analytical philosophers continue to distinguish in kind between "conceptual" and "empirical" issues.

10 Externalist accounts of epistemic justification, such as reliabilism or information-theoretic epistemology, are designed to scuttle internalist worries about justification. However, externalist accounts of justification only pertain to sensory knowledge, while identifying and justifying our claims about principles, whether epistemic or moral, raises these issues again. Hegel's theory of perceptual knowledge includes reliabilism about our perceptual neuropsychology.

11 Other contributors translate Hegel's term 'Gestalt' differently, e.g., by 'shape' or 'figure'. - Ed.

12 Hegel indicates this in stating that, "the moments of truth present themselves, not as abstract, pure moments, but in the peculiar determinateness of being as they are for consciousness, or as consciousness itself appears in relationship to them" (PS 61.33$36 /$ M 56).

13 On Hegel's further discussion of skepticism in the Introduction, see pp. 60-64. - Ed.

14 Recall Hegel's aphorism in the Preface: "in general what is familiar (bekannt), precisely because it is familiar, is not known (erkannt)" (PS 26.21/M 18); cf. MM 20:352, H\&S 3:444, B/HP 3:237.

15 Hegel states: "at that point where its appearance becomes identical to its essence, consciousness' presentation will thus converge with this very same point in the science of spirit proper. And, finally, since consciousness itself grasps this its essence, it will indicate the nature of absolute knowing itself" (PS 61.31-62.5/M 56-7; cf. PS 431.36-432.1, 432.14-16/M 490, 491).

16 "Sense Certainty" designates Hegel's chapter, Sense Certainty (without quotes) designates the form of consciousness examined in this chapter, sense certainty (without capitals) designates the philosophical view, the key ideas, of Sense Certainty - and analogously for Hegel's next two chapters.

17 These paragraph numbers indicate paragraphs within Hegel's chapter; they do not correspond to Miller's paragraph numbering. Introduction: PS 63-64.28/M 58-9, Phase I: PS 64.29-66.11/M 59-61, Phase II: PS 66.12-67.8/M 61-2, Phase III: PS 67.9-68.33/M 62-4, Conclusion: PS 68.34-70/M 64-6.

18 See Evans (1982, chapter 6); Kaplan (1989); Perry (1979). A 'token' is a specific instance, a specific use of a repeatable word ('type'). 
19 PS 66.18-19/M 61. Hegel's examples are deliberate. "Tree" and, less frequently, "house" run through the modern Empiricists as obvious examples of commonsense physical objects, or particulars. Both Locke and Berkeley use "tree" as an obvious example of what is meant by a physical substance (Locke 1975, 174, 330, cf. 409); (Berkeley 1975, 23, 77, 173, 180, 186). Most significant in the present context, "tree" and "house" are two of Hylas's key examples of physical objects that obviously exist without the mind, against which Philonous argues on behalf of Berkeley (Berkeley $1975,158)$. Hume $(1975,152)$ then uses these same examples to endorse this argument from Berkeley. (Cinzia Ferrini kindly reminded me of Hylas's use of these examples.)

20 Here Hegel's analysis coincides with Evans (1975); see Westphal (2006).

21 On Hegel's critique of skepticism, see below, pp. 60-64. - Ed.

22 Hegel's contrast between representations and concepts (Begriffe) is central to his contrast between "Understanding" and "Reason" and to his transition from "Religion" to "Absolute Knowing" ( PS 422.3-10/M 479); see below, pp. 23-24, 55-58, 77-78, 249-250, 254-255. - Ed.

23 "The riches of sensuous knowledge belongs to perception, not to immediate certainty, ... for only perception has negation, difference or manifoldness within its essence" (PS 71.30-33/M 67). These last three characterizations all stem from admitting general concepts in order to comprehend general properties of things.

24 Although Hegel speaks of "properties" (PS 72.12-14/M 68), he immediately adds: "these determinatenesses... strictly are properties only insofar as they first receive a further determination..." (PS 72.14-16/M 68).

25 Introduction: III-6 PS 71-74.11/M 67-70; Phase I: II77-8, PS 74.12-75.28/M 70-2; Phase II: Iโ[9-12, PS 75.29-77.12/M 72-4; Phase III: III3-18, PS 77.1379.10/M 74-6; conclusion: III19-21 PS 79.11-81.14/M 76-9.

26 The verb 'to posit' has entirely ordinary, proper sense both in English and in German ('setzen'); it has the sense of 'to take a position' by positing, e.g., a premise or an hypothesis. By itself this verb connotes nothing about excogitating objects into existence.

27 Wolff $(1981,35-6)$.

28 In a word, Hegel's "dialectical" contradictions (relations of mutual interdependence among contraposed aspects of something) are required for the very possibility of the phenomenon in question; in this they differ altogether from formal-logical contradictions which suffice to show the impossibility of something.

29 Roskies (1999), Cleeremans (2003).

30 I am deeply indebted to Harper (2002a, 2002b, forthcoming); I am very grateful to Harper for kindly sharing his MS with me prior to its publication.

31 Cassirer (1971, 2:407): “physikalischer Wesen”; Bloch (1908, 452): "L' «essence» matérielle de la lumière."

32 Newton (1952, 404-5, cf. 376). Cassirer and Bloch focus on the portentous shift from qualitative to quantitative physics, while neglecting the issue central here of how properly to interpret the quantified laws and regularities obtained by (sound) quantitative physics.

33 See Cassirer (1971, 2:405-6), Keill (1725, 8/1726, 6-7); cf. Cohen (1999) on "the Newtonian Style."

34 Much of Hegel's criticism of Newton is directed to his mathematical methods; the problems Hegel notes are resolved once Newtonian mechanics is rewritten by Johann Bernoulli, using analysis. (Some of Hegel's criticism of Newton is discussed below, chapter $5 .-E d$.)

35 There are further subtleties to Hegel's view not developed in "Force and Understanding." Hegel expressly refers to the Science of Logic for thorough analysis (PS 101.27/M 102), though he also discusses some of these issues in "Observing Reason." (See below, 
chapter 5, $\$ 1.2 .-E d$.) Very briefly, Hegel contends that the key concepts and principles of the natural sciences require careful philosophical reconstruction. Hegel's view that philosophical demonstrations cannot be approximate is consistent with the approximative, increasingly precise quantification and explanation of the physical sciences because the philosophical point Hegel justifies concerns the legitimate naturalscientific ascription of fundamental characteristics, such as gravity, to matter. This philosophical point is unaffected by the shift from Newtonian to Einsteinian mechanics.

36 Surprisingly, Wittgenstein develops the same kind of argument in later sections of his Philosophical Investigations; see Westphal (2005).

37 This same transcendental and cognitive semantic support of Newton's Rule Four is provided by Kant's own cognitive semantics, as I reconstruct it in Westphal (2004). This is my belated reply to Bill Harper's $(2007,734)$ kind question, whether Kant's epistemology, so reconstructed, provides significant support for Newton's very rich method for natural philosophy.

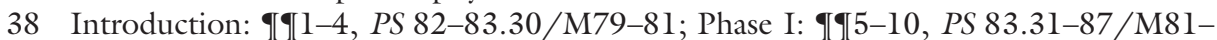
86; Phase II: III11-17, PS 88-91.16/M86-90; Phase III: III18-30, PS 91.17-99.29/ M90-100; Conclusion: III32-34, PS 99.30-102/M100-103.

39 See Plato, Theatetus 182; Sextus Empiricus, PH 1: 87, 2: 72-73; Locke, Essay 1.4.18, 1.8.21, 2.23.2, 2.23.28; Kant, CPR A251; and Putnam (1980, 475-6; 1981, chapters 1, 3, esp. $60-3 ; 1977,125,127,133$.) For illuminating discussion of Herder's views, see Proß (1994), Westphal $(2008-09, \$ 4.5)$.

40 The relevance of Newtonian gravitation to Hegel's analysis cannot be examined here; see Westphal (2008a).

41 The most recent explicit debate about logical identity and ontological atomism familiar to me is between Will (1940) and Church (1942). On Hegel's use of 'contradiction', see Wolff (1981).

42 The close links Hegel forges in "Force and Understanding" between epistemology and natural science are developed further in "Reason Observing Nature"; see below, chapter 5. $-E d$.

43 Hegel thus affirms realism about the objects of natural science, whereas Brandom denies it; see Rosenkranz (2001).

44 PS 359-62/M 405-9; Westphal (1989, 183).

45 PS 359.9-23, 360.31-361.4, .22-25, 362.21-29/M 407-9.

46 For discussion, see Westphal (2009b).

47 The reader is referred to the subsequent chapters which examine each section of Hegel's Phenomenology. - Ed.

48 Einstein $(2000,314)$.

49 The systematic character of Hegel's examination of human knowing is at odds with the piecemeal approach to dissolving or resolving problems still predominant among analytic epistemologists. However, this piecemeal approach was undermined by Carnap (1950); see Wick (1951), Westphal (1989, chapter 4).

50 Hegel's semantics of cognitive reference appears to provide his premises for his account of thought in the second part of "Self-Consciousness"; see below, chapters 3-6. - Ed.

51 I gratefully acknowledge the financial support provided me by the Alexander von Humboldt-Stiftung for my research on "Perception" (1995) and on "Force and Understanding" (2007). I also wish to thank Hans-Friedrich Fulda and Martin Carrier, respectively, for hosting and so productively engaging with my research.

52 'T.s.' is logician's shorthand for 'to show', following which a thesis (conclusion) is stated, for which Hegel argues by reductio ad absurdum through internal phenomenological critique of the form(s) of consciousness espousing the opposite thesis. This chart is revised from previous versions. 
Concepts are a priori when they can be neither defined nor learned on the basis of sensory experience alone, as understood by empiricists (Concept Empiricism); they are 'pure' a priori when they are required for us to learn, define, or use any concepts that are learned or defined in terms of sensory experience.

Hegel twice identifies the topic of his section on "Spirit" as "immediate spirit" ( $G W$ 9:240.1-4, 365.23/M 265, 413).

\section{References}

Anon. (Christian Huygens) (1673) "An Extract of a Letter Lately Written by an Ingenious Person from Paris, Containing Some Considerations upon Mr. Newtons Doctrine of Colors, as Also upon the Effects of the Different Refractions of the Rays in Telescopical Glasses,” Philosophical Transactions 8:6086-6087 (DOI: 10.1098/ rstl.1673.0034).

Berkeley, George (1975) Philosophical Works, including the works on vision, ed. M. R. Ayers. London: Dent; Totowa, NJ: Rowman \& Littlefield.

Bloch, Léon (1908) La philosophie de Newton. Paris: F. Alcan. Rpt. by The Canadian Libraries Internet Archive, http://www.archive.org/details/ laphilosophieden00blocuoft (accessed May 8, 2008).

Bonjour, Laurence (1997) "Haack on Justification and Experience," Synthese 112: $13-23$.

Carnap, Rudolf (1950) "Empiricism, Semantics and Ontology," Revue International de Philosophie 4; rev. ed. in Rudolf Carnap (1956) Meaning and Necessity (pp. 205-21). Chicago: University of Chicago Press.

Cassirer, Ernst (1971) Das Erkenntnisproblem in der Philosophie und Wissenschaft der neueren Zeit, 4 vols. Hildesheim: Olms.

Church, Ralph (1942) "Bradley's Theory of Relations and the Law of Identity," The Philosophical Review 51.1: 26-46.

Cleeremans, Axel (ed.) (2003) The Unity of Consciousness: Binding, Integration and Dissociation. Oxford: Oxford University Press.

Cohen, I. Bernard (1999) "A Guide to Newton's Principia," in Newton (1999), pp. $1-370)$.

Descartes, René (1964-). Oevres de Descartes, 13 vols., ed. C. Adam and P. Tannery, rev. ed. Paris: Vrin/C.N.R.S.

Descartes, René (1984-) The Philosophical Writings of Descartes, 3 vols., tr. J. Cottingham, R. Stoothoff, and D. Murdoch. Cambridge: Cambridge University Press.

Einstein, Albert (2000) The Expanded Quotable Einstein, ed. A. Calaprice. Princeton: Princeton University Press.

Evans, Gareth (1975) "Identity and Predication," Journal of Philosophy 72.13: 343-63; rpt. in Gareth Evans (1985), Collected Papers (pp. 25-48). Oxford: The Clarendon Press.

Evans, Gareth (1982) The Varieties of Reference, ed. J. McDowell. Oxford: The Clarendon Press.

Harper, William (2002a), "Howard Stein on Isaac Newton: Beyond Hypotheses?," in D. Malament (ed.), Reading Natural Philosophy (pp. 71-111). Chicago: University of Chicago Press.

Harper, William (2002b) "Newton's Argument for Universal Gravitation," in I. B. Cohen and G. Smith (eds.), The Cambridge Companion to Newton (pp. 174-201). Cambridge: Cambridge University Press.

Harper, William (2007) “Comments on Westphal,” Dialogue 46: 729-36. 
Harper, William (forthcoming) Isaac Newton's Scientific Method: Turning Data into Evidence for Universal Gravity. New York: Oxford University Press.

Hooke, Robert (1667) Micrographia or some Physiological descriptions of minute bodies. London (n.p.); rpt. by The University of Wisconsin Digital Collection, http:// digicoll.library.wisc.edu/cgi-bin/HistSciTech/HistSciTech-idx?type=turn\&entity=Hi stSciTech001303260108\&isize $=M$ (accessed May 8, 2008).

Hume, David (1975) An Enquiry Concerning Human Understanding, in P. H. Nidditch (ed.), Enquiries Concerning Human Understanding and Concerning the Principles of Morals, 3rd ed. Oxford: The Clarendon Press.

Hume, David (2000) A Treatise of Human Nature, ed. D. F. Norton and M. J. Norton. Oxford: Oxford University Press.

Kaplan, David (1989) "On Demonstratives" (1977), in J. Almog et al. (eds.), Themes from Kaplan (pp. 481-563). New York: Oxford University Press.

Keill, John (1725) Introductio ad veram physicam, 3rd ed. Oxford: Bennet.

Keill, John (1726) Introduction to Natural Philosophy, 2nd ed. London: Innys.

Locke, John (1975) An Essay Concerning Human Understanding, ed. P. H. Nidditch. Oxford: The Clarendon Press.

Newton, Sir Isaac (1673) “Mr. Newton's Answer to the Foregoing Letter Further Explaining His Theory of Light and Colors, and Particularly That of Whiteness; together with His Continued Hopes of Perfecting Telescopes by Reflections Rather than Refractions," Philosophical Transactions 8: 6087-6092 (DOI: 10.1098/ rstl.1673.0035).

Newton, Sir Isaac (1952) Opticks. New York: Dover (rev. ed. 1979).

Newton, Sir Isaac (1999) The Principia: Mathematical Principles of Natural Philosophy, tr. I. Bernard Cohen and Anne Whitman, with assistance from Julia Budenz. Berkeley: University of California Press.

Perry, John (1979) “The Problem of the Essential Indexical," Nous 13: 3-21.

Plato (1997) Complete Works, ed. J. M. Cooper, with D. S. Hutchinson. Cambridge, Mass.: Hackett Publishing Co.

Proß, Wolfgang (1994) "Herders Konzept der organischen Kräfte und die Wirkung der Ideen zur Philosophie der Geschichte der Menschbeit auf Carl Friedrich Kielmeyer," in K. T. Kanz (ed.), Philosophie des Organischen in der Goethezeit. Studien zu Werk und Wirkung des Naturforschens Carl Friedrich Kielmeyer (1765-1844) (pp. 81-99). Stuttgart: Steiner.

Putnam, Hilary (1977) "Realism and Reason," Proceeding and Addresses of the American Philosophical Association 50 (1976-77); rpt. in Hilary Putnam, Meaning and the Moral Sciences (pp. 123-40). London: Routledge \& Kegan Paul.

Putnam, Hilary (1980) "Models and Reality," Journal of Symbolic Logic 45.3: 46482.

Putnam, Hilary (1981) Reason, Truth, and History. Cambridge, Mass.: Harvard University Press.

Rosenkranz, Sven (2001) "Farewell to Objectivity: A Critique of Brandom," The Philosophical Quarterly 51.203: 232-7.

Roskies, Adina (ed.) (1999) “The Binding Problem," Neuron 24: 7-125.

Sextus Empiricus (1934) Ontlines of Pyrrhonism [cited as ' $P H$ '], tr. R. G. Bury, in Works, 4 vols., vol. 1. Cambridge, Mass.: Harvard University Press.

Westphal, Kenneth R. (1989) Hegel's Epistemological Realism: A Study of the Aim and Method of Hegel's Phenomenology of Spirit. Philosophical Studies Series in Philosophy, ed. K. Lehrer, vol. 43. Dordrecht and Boston: Kluwer.

Westphal, Kenneth R. (2004) Kant's Transcendental Proof of Realism. Cambridge: Cambridge University Press.

Westphal, Kenneth R. (2005) “Kant, Wittgenstein, and Transcendental Chaos," Philosophical Investigations 28.4: 303-23. 
Westphal, Kenneth R. (2006) "Contemporary Epistemology: Kant, Hegel, McDowell," The European Journal of Philosophy 14.2: 274-302; rpt. in J. Lindgaard (ed.), McDowell: Experience, Norm and Nature (pp. 124-151). Oxford: Blackwell, 2008.

Westphal, Kenneth R. (2007) "Force, Understanding and Ontology," Bulletin of the Hegel Society of Great Britain $57 / 58$.

Westphal, Kenneth R. (2007-08) 'Intelligenz and the Interpretation of Hegel's Idealism: Some Hermeneutic Pointers,' The Owl of Minerva 39.1-2: 95-134.

Westphal, Kenneth R. (2009a) "Philosophizing about Nature: Hegel's Philosophical Project," in F. C. Beiser (ed.), The Cambridge Companion to Hegel and Nineteenth Century Philosophy (pp. 281-310). Cambridge: Cambridge University Press.

Westphal, Kenneth R. (2009b). "Urteilskraft, gegenseitige Anerkennung und rationale Rechtfertigung," in H.-D. Klein (ed.), Ethik als prima philosophia? Würzburg: Königshausen \& Neumann.

Wick, Warner (1951) “The 'Political' Philosophy of Logical Empiricism," Philosophical Studies 2.4: 49-57.

Will, Frederick L. (1940) "Internal Relations and the Principle of Identity," The Philosophical Review 49.5: 497-514.

Wolff, Michael (1981) Der Begriff des Widerspruchs. Eine Studie zur Dialektik Kants und Hegels. Königstein/Ts.: Hain.

\title{
Further Reading
}

\author{
Hegel's Introduction:
}

Westphal, Kenneth R. (1989) Hegel's Epistemological Realism: A Study of the Aims and Methods of Hegel's Phenomenology of Spirit. Dordrecht and Boston: Kluwer.

Westphal, Kenneth R. (1998) "Hegel's Solution to the Dilemma of the Criterion," rev. ed. in J. Stewart (ed.), The Phenomenology of Spirit Reader: A Collection of Critical and Interpretive Essays (pp. 76-91). Albany: State University of New York Press.

\section{"Sense Certainty":}

deVries, Willem (2008) "Sense Certainty and the 'This-Such'," in D. Moyar and M. Quante (eds.), Hegel's 'Phenomenology of Spirit': A Critical Guide (pp. 63-75). Cambridge: Cambridge University Press.

Westphal, Kenneth R. (2000) "Hegel's Internal Critique of Naïve Realism," Journal of Philosophical Research 25: 173-229.

Westphal, Kenneth R. (2002) “'Sense Certainty', or Why Russell Had No 'Knowledge by Acquaintance'," The Bulletin of the Hegel Society of Great Britain 45/46: 110-23.

Westphal, Kenneth R. (2005) "Hume, Hegel, and Abstract General Ideas," Bulletin of the Hegel Society of Great Britain 51/52: 28-55.

\section{"Perception":}

Westphal, Kenneth R. (1996) "Vom Skeptizismus in Bezug auf die Sinne oder das Ding und die Täuschung," in H. F. Fulda and R.-P. Horstmann (eds.), Skeptizismus und Spekulatives Denken in der Philosophie Hegels (pp. 153-76). Stuttgart: Klett-Cotta.

Westphal, Kenneth R. (1998) Hegel, Hume und die Identität wahrnehmbarer Dinge. Historisch-kritische Analyse zum Kapitel "Wahrnehmung” in der Phänomenologie von 1807. Frankfurt am Main: Klostermann. 
Westphal, Kenneth R. (1998) "Hegel and Hume on Perception and Concept-Empiricism," Journal of the History of Philosophy 33.1: 99-123.

\section{"Force and Understanding":}

Westphal, Kenneth R. (2006) "Science and the Philosophers," in H. Koskinen, S. Pihlström, and R. Vilkko (eds.), Science: A Challenge to Philosophy? (pp. 125-52). Frankfurt am Main: Lang.

Westphal, Kenneth R. (2008) "Force, Understanding and Ontology," Bulletin of the Hegel Society of Great Britain $57 / 58$.

Westphal, Kenneth R. (2008) "Philosophizing about Nature: Hegel's Philosophical Project," in F. C. Beiser (ed.), The Cambridge Companion to Hegel and Nineteenth Century Philosophy (pp. 281-310). Cambridge: Cambridge University Press.

\section{Hegel's Epistemology in the Phenomenology:}

Westphal, Kenneth R. (1998) "Harris, Hegel, and the Spirit of the Phenomenology," Clio 27.4: $551-72$.

Westphal, Kenneth R. (2002/2003) "Die Vielseitigkeit von Hegels Auseinandersetzung mit Skeptizismus in der Phänomenologie des Geistes," Jahrbuch für Hegel-Forschungen 8/9: 145-73.

Westphal, Kenneth R. (2003a) Hegel's Epistemology: A Philosophical Introduction to the Phenomenology of Spirit. Cambridge, Mass.: Hackett Publishing Co.

Westphal, Kenneth R. (2003b) "Hegel's Manifold Response to Scepticism in the Phenomenology of Spirit," Proceedings of the Aristotelian Society 103.2: 149-78.

Westphal, Kenneth R. (2006) "Contemporary Epistemology: Kant, Hegel, McDowell," The European Journal of Philosophy 14.2: 274-302; rpt. in Jacob Lindgaard (ed.), McDowell: Experience, Norm and Nature (pp. 124-151). Oxford: Blackwell, 2008.

Westphal, Kenneth R. (2009) "Urteilskraft, gegenseitige Anerkennung und rationale Rechtfertigung," in H.-D. Klein (ed.), Ethik als prima philosophia? Würzburg: Königshausen \& Neumann.

Westphal, Kenneth R. (2009) "Consciousness, Scepticism and the Critique of Categorial Concepts in Hegel's 1807 Phenomenology of Spirit," in M. Bykova (ed.), Сущность, Явление и Феномен. К Юбилею Нели Васильевны Мотрошиловой (Essence, Appearance, and Phenomena. Festschrift for Nelly V. Motroshilova). Moscow: Hermeneutics \& Phenomenology Press. 